\title{
XRCC1 mediated the development of cervival cancer through a novel Sp1/Krox-20 swich
}

\author{
Qingtao Meng ${ }^{1, *}$, Shizhi Wang ${ }^{1, *}$, Weiyan Tang $^{2, *}$, Shenshen Wu ${ }^{1}$, Na Gao ${ }^{3}$, \\ Chengcheng Zhang ${ }^{1}$, Xiaoli $\mathrm{CaO}^{4}$, Xiaobo $\mathrm{Li}^{1}$, Zhengdong Zhang ${ }^{5}$, Michael Aschner ${ }^{6}$ \\ Hua Jin ${ }^{7, * *}$, Yue Huang ${ }^{8, * *}$ and Rui Chen ${ }^{1,9, * *}$ \\ ${ }^{1}$ Key Laboratory of Environmental Medicine Engineering, Ministry of Education, School of Public Health, Southeast University, \\ Nanjing, China \\ ${ }^{2}$ Medical Oncology, Jiangsu Cancer Hospital, Nanjing, China \\ ${ }^{3}$ Institute of Bioinformatics, Heinrich Heine University, Düsseldorf, Germany \\ ${ }^{4}$ Clinical Lab, Nantong Tumor Hospital, Nantong, China \\ ${ }^{5}$ Department of Environmental Genomics, Jiangsu Key Laboratory of Cancer Biomarkers, Prevention and Treatment, Cancer \\ Center, Nanjing Medical University, Nanjing, China \\ ${ }^{6}$ Department of Molecular Pharmacology, Albert Einstein College of Medicine, Bronx, NY, USA \\ ${ }^{7}$ Core Laboratory, Nantong Tumor Hospital, Nantong, China \\ ${ }^{8}$ Department of Pathology, Nanjing First Hospital, Nanjing Medical University, Nanjing, China \\ ${ }^{9}$ State Key Laboratory of Respiratory Disease, Institute for Chemical Carcinogenesis, Guangzhou Medical University, \\ Guangzhou, China \\ *These authors have contributed equally to this work \\ *** These authors co-supervised this work \\ Correspondence to: Rui Chen, email: 101011816@seu.edu.cn \\ Yue Huang, email: redxxy@163.com \\ Hua Jin, email: ntmgjh@163.com
}

Keywords: base excision repair, XRCC1, cervical cancer, Krox-20, specificity protein 1

Received: June 29, $2017 \quad$ Accepted: August 09, $2017 \quad$ Published: September 16, 2017

Copyright: Meng et al. This is an open-access article distributed under the terms of the Creative Commons Attribution License 3.0 (CC BY 3.0), which permits unrestricted use, distribution, and reproduction in any medium, provided the original author and source are credited.

\section{ABSTRACT}

Cervical cancer is the second leading cause of mortality among women. Impairment of the base excision repair (BER) pathway is one of the major causes of the initiation and progression of cervical cancer. However, whether the polymorphisms of the BER pathway components (i.e., HOGG1, XRCC1, ADPRT, and APE1) can affect the risk of cervical cancer remains unknown. Herein, we applied a hospital-based case-control study covering two independent cohorts and a subsequent functional assay to determine the roles of the single nucleotide polymorphisms (SNPS) of the BER pathway genes in cervical cancer. Results indicated that the XRCC1 rs3213245 (-77TC) TT genotype was associated with an increased risk of cervical cancer. The immunohistochemistry assay showed that XRCC1 protein expression levels were upregulated in cervical cancer patients with the XRCC1 rs3213245 CC genotype compared with the CT or TT genotypes. Further, results from ChIP assay showed that Sp1 could bind to the -77 site and that the rs3213245 C genotype promoted the binding of Sp1 to the XRCC1 promoter. Moreover, $\mathrm{ChIP} / \mathrm{Re}$-ChIP assays revealed that transcription factor Krox-20 was recruited to the XRCC1 rs3213245 mutation region and regulated the transcription of the XRCC1 gene by interacting with Sp1, ultimately mediated cervical cancer development. In summary, the findings indicated that the functional XRCC1 SNP rs3213245 was associated with the risk of cervical cancer based on the Sp1/Krox-20 switch. 


\section{INTRODUCTION}

Cervical cancer is the second most common malignant tumor found in women worldwide accounting for $7.5 \%$ of all female cancer deaths [1]. The base excision repair (BER) pathway is responsible for repairing the DNA single-strand breaks caused by oxidative stress (such as reactive oxygen species, ROS), thereby maintaining genomic integrity. Impaired BER pathways are considered the major cause of cervical cancer [2]. However, it remains unknown whether the genetic polymorphisms of the key modulators in the BER pathway affect cervical cancer susceptibility.

The apurinic/apyrimidinic endonuclease 1 (APE1), adenosine diphosphate ribosyltransferase (ADPRT), human oxoguanine glycosylase 1 (HOGG1) and X-ray cross complementing group 1 (XRCC1) are important regulators of the BER pathway. The abasic (AP) site aroused by DNA single-strand breaks can be recognized and excised by $A P E 1$. The association between $A P E 1$ rs1760944 (-656T $>\mathrm{G})$ and rs1130409 (Asp148Glu) polymorphisms and the risk of renal cell carcinoma and breast cancer have been indicated in several casecontrol studies [3, 4]. HOGG1 removes 8-oxoG from the damaged DNA for further repair [5]. However, the HOGG1 (rs1052133) Ser genotype has failed to repair broken DNA and has been demonstrated to increase cancer susceptibility in the gallbladder cancer [6] and renal cell carcinoma [7]. Few studies have focused on the HOGG1 genetic variants and cervical cancer susceptibility. XRCC1 serves as the scaffold protein in the BER pathway, which recognizes DNA breaks and interacts with DNA polymerase $\beta$, DNA ligase III, and other components to repair Single-Strand Breaks (SSBs) [8]. Many studies have demonstrated that XRCC1 polymorphisms (i.e., rs1799782, Arg194Trp; rs25489, Arg280His; and rs25487, Arg399Gln) are associated with increased risk of cancer $[9,10]$. The rs3213245 polymorphism located in the XRCC1 promoter is associated with the enhanced risk of breast and lung cancer [11, 12]. Moreover, rs3213245 (-77TC) alters the affinity of several transcription factors binding to the promoter, such as specificity protein 1 (Sp1) [13]. Sp1, which is one of the bestcharacterized transcriptional activators [14], plays a prominent role in cell-cycle development and regulation [15-18].

In the present study, case-control studies were conducted to analyze the association between the polymorphisms of BER components and the risk of cervical cancer in a Chinese population. Further, ChIP/ Re-ChIP and IHC assays were also performed to evaluate the roles of these SNPs in cervical cancer.

\section{RESULTS}

\section{Demographic and clinical characteristics of the study subjects}

The clinical characteristics of the enrolled testing and validation cohorts were evaluated (Table 1). No significant differences in age distribution $(P=0.726)$ or abortion $(P=0.565)$ were detected between cases and controls in the testing cohort. However, more cases with higher parity $(\geq 2)(41.7 \%)$ and premenopausal status $(44.0 \%)$ were observed. Moreover, most of the cases with cervical cancer, have been diagnosed as squamous-cell carcinoma (94.2\%) at the first stage of invasion (68.0\%). The demographic and clinical characteristics of the subjects in the validation cohort were almost the same with those in the testing cohort (Table 1).

\section{HOGG1, XRCC1, ADPRT, and APE1 polymorphisms and risk of cervical cancer}

The genetic variants of the key components (i.e., $H O G G 1, X R C C 1, A D P R T$, and APE1) in the BER pathway and the risk of cervical cancer in the testing cohort were analyzed. The genotypic frequencies of the selected polymorphisms did not deviate significantly from HardyWeinberg values in either test cases or controls (Table 2, $P>0.05$ for the combined set). The results showed that the XRCC1 (rs3213245) TT genotype increased the risk of cervical cancer (adjusted OR $=0.63 ; 95 \% \mathrm{CI}=0.46-$ 0.86 for the testing set; adjusted $\mathrm{OR}=0.57 ; 95 \% \mathrm{CI}=$ $0.44-0.73$ for the validation set; and adjusted $\mathrm{OR}=0.62$, $95 \% \mathrm{CI}=0.51-0.75$ for the combined set, TT genotype reference). However, no significant associations were observed between the HOGG1 (rs1052133, Ser326Cys), XRCC1 (rs1799782, Arg194Trp; rs25487, Arg399Gln; rs25489, Arg280His), ADPRT (rs1136410, Val762Ala), or APE1 (rs1130409, Asp148Glu; rs1760944, -656TG) polymorphisms and the risk of cervical cancer (Table 2).

The associations between these genetic variants and the risk of cervical cancer were further evaluated by stratification analysis. As showed in Table 3, the XRCC1 (rs3213245) TT genotype increased the risk of cervical cancer in the subgroups of aged $>49$ years (adjusted OR $=0.47,95 \% \mathrm{CI}=0.36-0.62$, TT genotype reference). We also observed a similar result in each subgroups of parity, abortion, and premenopausal status. Moreover, a significantly increased risk was also found in the early stage of cervical cancer (adjusted OR $=0.63,95 \% \mathrm{CI}=$ $0.52-0.76$, TT genotype reference).

XRCC1 rs3213245 TT genotype decreased XRCC1 protein expression through effecting the binding affinity of Sp1/Krox-20 to the XRCC1 promoter

To further determine whether the XRCC1 rs3213245 polymorphism can affect its protein expression, a total of 
Table 1: Frequency distribution of select characteristics in cervical cases and controls

\begin{tabular}{|c|c|c|c|c|c|c|}
\hline \multirow{3}{*}{ Variables $^{\mathrm{a}}$} & \multicolumn{2}{|c|}{ Test set } & \multirow{3}{*}{$P$} & \multicolumn{2}{|c|}{ Validation set } & \multirow{3}{*}{$P$} \\
\hline & Cases & Controls & & Cases & Controls & \\
\hline & $\mathrm{n}=571(\%)$ & $\mathrm{n}=657(\%)$ & & $n=608(\%)$ & $\mathrm{n}=1165(\%)$ & \\
\hline $\begin{array}{l}\text { Age, year (mean } \pm \\
\text { SD) }\end{array}$ & $47.5 \pm 10.1$ & $47.3 \pm 10.6$ & 0.726 & $51.5 \pm 9.4$ & $51.6 \pm 10.7$ & 0.971 \\
\hline \multicolumn{7}{|l|}{ Parity } \\
\hline $0-1$ & $324(58.3)$ & $446(75.2)$ & $<0.001$ & $323(54.2)$ & $800(72.6)$ & $<0.001$ \\
\hline$\geq 2$ & $232(41.7)$ & $147(24.8)$ & & $273(45.8)$ & $302(27.4)$ & \\
\hline \multicolumn{7}{|l|}{ Abortion } \\
\hline No & $377(70.5)$ & $402(72.0)$ & 0.565 & $242(40.7)$ & $454(41.5)$ & 0.762 \\
\hline Yes & $158(29.5)$ & $156(28.0)$ & & $352(59.3)$ & $640(58.5)$ & \\
\hline \multicolumn{7}{|l|}{ Menopausal status } \\
\hline Premenopausal & $240(44.0)$ & $127(21.1)$ & $<0.001$ & $318(52.65)$ & $436(39.7)$ & $<0.001$ \\
\hline Postmenopausal & $306(56.0)$ & $476(78.9)$ & & $286(47.35)$ & $661(60.3)$ & \\
\hline \multicolumn{7}{|l|}{ Histologic types } \\
\hline $\begin{array}{l}\text { Squamous cell } \\
\text { carcinoma }\end{array}$ & $538(94.2)$ & & & $550(90.5)$ & & \\
\hline Adenocarcinomas & $24(4.2)$ & & & $31(5.1)$ & & \\
\hline $\begin{array}{l}\text { Adenosquamous } \\
\text { carcinoma }\end{array}$ & $4(0.7)$ & & & $16(2.6)$ & & \\
\hline Others $^{b}$ & $5(0.9)$ & & & $11(1.8)$ & & \\
\hline \multicolumn{7}{|l|}{ Stage } \\
\hline I & $383(68.0)$ & & & $391(64.3)$ & & \\
\hline II & $145(25.8)$ & & & $209(34.4)$ & & \\
\hline III & $28(5.0)$ & & & $2(0.3)$ & & \\
\hline IV & $7(1.2)$ & & & $6(1.0)$ & & \\
\hline
\end{tabular}

a Some cases lack information of selected variables.

${ }^{\mathrm{b}}$ Other histological types, such as cervical choriocarcinoma.

60 paraffin-embedded tissue sections were selected for immunohistochemistry (IHC) analysis. The frequency distributions of the XRCC1 rs3213245 CC, CT, and TT genotypes were 12,24 , and 24 , respectively. The IHC assay showed that the XRCC1 protein expression levels were upregulated in cervical cancer patients with the XRCC1 rs3213245 CC genotype compared with the CT or TT genotypes according to the staining scores (Figure $1 \mathrm{~A}$ and $1 \mathrm{~B})$.

The XRCC1 rs3213245 SNP was located at the -77 promoter site which was contained in the Sp1 binding motif according to the Alibaba2 Bioinformatics database (Figure 1C). It is here hypothesized that the genetic variant might alter the XRCC1 transcription factor affinity on the Sp1 binding site. In this case, the mechanisms of action were determined and the ability of Sp1 to bind to the -77 site with ChIP analysis was assessed. Finally, a total of 9 cervical cancer patients with three different combined genotypes was selected to perform the ChIP and Re-ChIP experiments. Results indicated that the rs3213245 C genotype dramatically promoted Sp1 binding to the XRCC1 promoter, but the TT genotype did not (Figure 1D). Inspired by the Alibaba2 Bioinformatics database, we then proposed that Krox-20, one transcription factor overlapped with Sp1, might be regulated by this SNP. The following in vivo ChIP assay further evaluated this hypothesis (Figure 1E). Thus, we speculated that $\mathrm{Sp} 1$ and Krox-20 might co-regulate the 
Table 2: Association between genetic polymorphisms in the base excision repair genes and cervical cancer risk

\begin{tabular}{|c|c|c|c|c|c|c|c|c|c|c|}
\hline \multirow[b]{2}{*}{ Genotype } & & \multicolumn{3}{|c|}{ Test set } & \multicolumn{3}{|c|}{ Validation set } & \multicolumn{3}{|c|}{ Combined set } \\
\hline & & Cases/controls & $\mathbf{P}$ & Adjusted OR & Cases/controls & $\mathbf{P}$ & $\begin{array}{l}\text { Adjusted } \\
\text { OR }\end{array}$ & Cases/controls & $\mathbf{P}$ & $\begin{array}{l}\text { Adjusted } \\
\text { OR }\end{array}$ \\
\hline \multirow[t]{6}{*}{ rs3213245 } & $\mathrm{TT}$ & $462 / 501$ & 0.0357 & & $493 / 841$ & 0.0002 & & $955 / 1342$ & $<.0001$ & \\
\hline & $\mathrm{TC}$ & $104 / 140$ & & $0.69(0.50-0.96)$ & $107 / 293$ & & $\begin{array}{c}0.58(0.45- \\
0.76)\end{array}$ & $211 / 433$ & & $\begin{array}{c}0.65(0.54- \\
0.80)\end{array}$ \\
\hline & $\mathrm{CC}$ & $5 / 16$ & & $0.13(0.03-0.49)$ & $8 / 31$ & & $\begin{array}{c}0.43(0.19- \\
0.97)\end{array}$ & $13 / 47$ & & $\begin{array}{c}0.31(0.16- \\
0.62)\end{array}$ \\
\hline & $\mathrm{TC} / \mathrm{CC}$ & $109 / 156$ & 0.048 & $0.63(0.46-0.86)$ & $115 / 324$ & $<.0001$ & $\begin{array}{c}0.57(0.44- \\
0.73)\end{array}$ & $224 / 480$ & $<.0001$ & $\begin{array}{c}0.62(0.51- \\
0.75)\end{array}$ \\
\hline & $\mathrm{C}$ allele & $0.0998 / 0.1309$ & & & $0.1012 / 0.1524$ & & & $0.1005 / 0.1446$ & & \\
\hline & HWE & $0.7479 / 0.1039$ & & & $0.4274 / 0.3695$ & & & $0.7256 / 0.0922$ & & \\
\hline \multirow[t]{5}{*}{ rs 1052133} & GG & $196 / 228$ & 0.3279 & & $216 / 414$ & 0.9103 & & $412 / 642$ & 0.7961 & \\
\hline & GC & $276 / 335$ & & $1.00(0.75-1.32)$ & $301 / 568$ & & $\begin{array}{c}1.05(0.83- \\
1.32)\end{array}$ & $577 / 903$ & & $\begin{array}{c}1.02(0.86- \\
1.21)\end{array}$ \\
\hline & $\mathrm{CC}$ & $99 / 94$ & & $1.36(0.92-1.99)$ & $91 / 183$ & & $\begin{array}{c}0.95(0.69- \\
1.31)\end{array}$ & $190 / 277$ & & $\begin{array}{c}1.07(0.85- \\
1.35)\end{array}$ \\
\hline & $\mathrm{C}$ allele & $0.4151 / 0.3980$ & & & $0.3972 / 0.4009$ & & & $0.4059 / 0.3998$ & & \\
\hline & HWE & $0.9135 / 0.1006$ & & & $0.4042 / 0.6083$ & & & $0.6119 / 0.1633$ & & \\
\hline \multirow[t]{5}{*}{ rs1760944 } & $\mathrm{AA}$ & $182 / 211$ & 0.976 & & $199 / 386$ & 0.9715 & & $381 / 597$ & 0.9301 & \\
\hline & $\mathrm{AC}$ & $285 / 324$ & & $1.01(0.75-1.34)$ & $298 / 564$ & & $\begin{array}{c}1.06(0.84- \\
1.35)\end{array}$ & $583 / 888$ & & $\begin{array}{c}1.02(0.86- \\
1.22)\end{array}$ \\
\hline & $\mathrm{CC}$ & $104 / 122$ & & $1.06(0.73-1.54)$ & $111 / 215$ & & $\begin{array}{c}1.04(0.77- \\
1.41)\end{array}$ & $215 / 337$ & & $\begin{array}{c}1.00(0.80- \\
1.26)\end{array}$ \\
\hline & $\mathrm{C}$ allele & $0.4317 / 0.4323$ & & & $0.4276 / 0.4266$ & & & $0.4296 / 0.4286$ & & \\
\hline & HWE & $0.6805 / 0.9033$ & & & $0.9757 / 0.7216$ & & & $0.7579 / 0.8315$ & & \\
\hline \multirow[t]{5}{*}{ rs1130409 } & $\mathrm{TT}$ & $182 / 192$ & 0.6014 & & $191 / 350$ & 0.7823 & & $373 / 542$ & 0.5295 & \\
\hline & TG & $282 / 338$ & & $0.95(0.71-1.26)$ & $304 / 586$ & & $\begin{array}{c}0.93(0.73- \\
1.18)\end{array}$ & $586 / 924$ & & $\begin{array}{c}0.93(0.78- \\
1.11)\end{array}$ \\
\hline & GG & $107 / 127$ & & $0.96(0.66-1.38)$ & $113 / 229$ & & $\begin{array}{c}0.94(0.69- \\
1.28)\end{array}$ & $220 / 356$ & & $\begin{array}{c}0.92(0.73- \\
1.15)\end{array}$ \\
\hline & $\begin{array}{c}\mathrm{G} \\
\text { allele }\end{array}$ & $0.4343 / 0.4505$ & & & $0.4359 / 0.4481$ & & & $0.4351 / 0.4490$ & & \\
\hline & HWE & $0.9034 / 0.3164$ & & & $0.6799 / 0.5622$ & & & $0.7034 / 0.2869$ & & \\
\hline \multirow[t]{5}{*}{ rs1136410 } & TT & $188 / 192$ & 0.2215 & & $254 / 425$ & 0.0898 & & $442 / 617$ & 0.087 & \\
\hline & $\mathrm{TC}$ & $280 / 325$ & & $0.92(0.69-1.23)$ & $256 / 529$ & & $\begin{array}{c}0.76(0.60- \\
0.95)\end{array}$ & $536 / 854$ & & $\begin{array}{c}0.85(0.72- \\
1.01)\end{array}$ \\
\hline & $\mathrm{CC}$ & $103 / 140$ & & $0.71(0.49-1.03)$ & $98 / 211$ & & $\begin{array}{c}0.78(0.57- \\
1.05)\end{array}$ & $201 / 351$ & & $\begin{array}{c}0.78(0.62- \\
0.98)\end{array}$ \\
\hline & $\mathrm{C}$ allele & $0.4256 / 0.4604$ & & & $0.3717 / 0.4082$ & & & $0.3978 / 0.4270$ & & \\
\hline & HWE & $0.9436 / 0.9098$ & & & $0.0151 / 0.0401$ & & & $0.0793 / 0.0720$ & & \\
\hline \multirow[t]{4}{*}{ rs1799782 } & $\mathrm{CC}$ & $270 / 287$ & 0.1799 & & $286 / 585$ & 0.4467 & & $556 / 872$ & 0.685 & \\
\hline & $\mathrm{CT}$ & $240 / 310$ & & $0.81(0.62-1.05)$ & $257 / 463$ & & $\begin{array}{c}1.09(0.87- \\
1.36)\end{array}$ & $497 / 773$ & & $\begin{array}{c}0.97(0.82- \\
1.14)\end{array}$ \\
\hline & TT & $61 / 60$ & & $1.05(0.68-1.64)$ & $65 / 117$ & & $\begin{array}{c}1.18(0.82- \\
1.68)\end{array}$ & $126 / 177$ & & $\begin{array}{c}1.11(0.85- \\
1.45)\end{array}$ \\
\hline & $\mathrm{T}$ allele & $0.317 / 0.3272$ & & & $0.3183 / 0.2991$ & & & $0.3176 / 0.3093$ & & \\
\hline
\end{tabular}

(continued) 


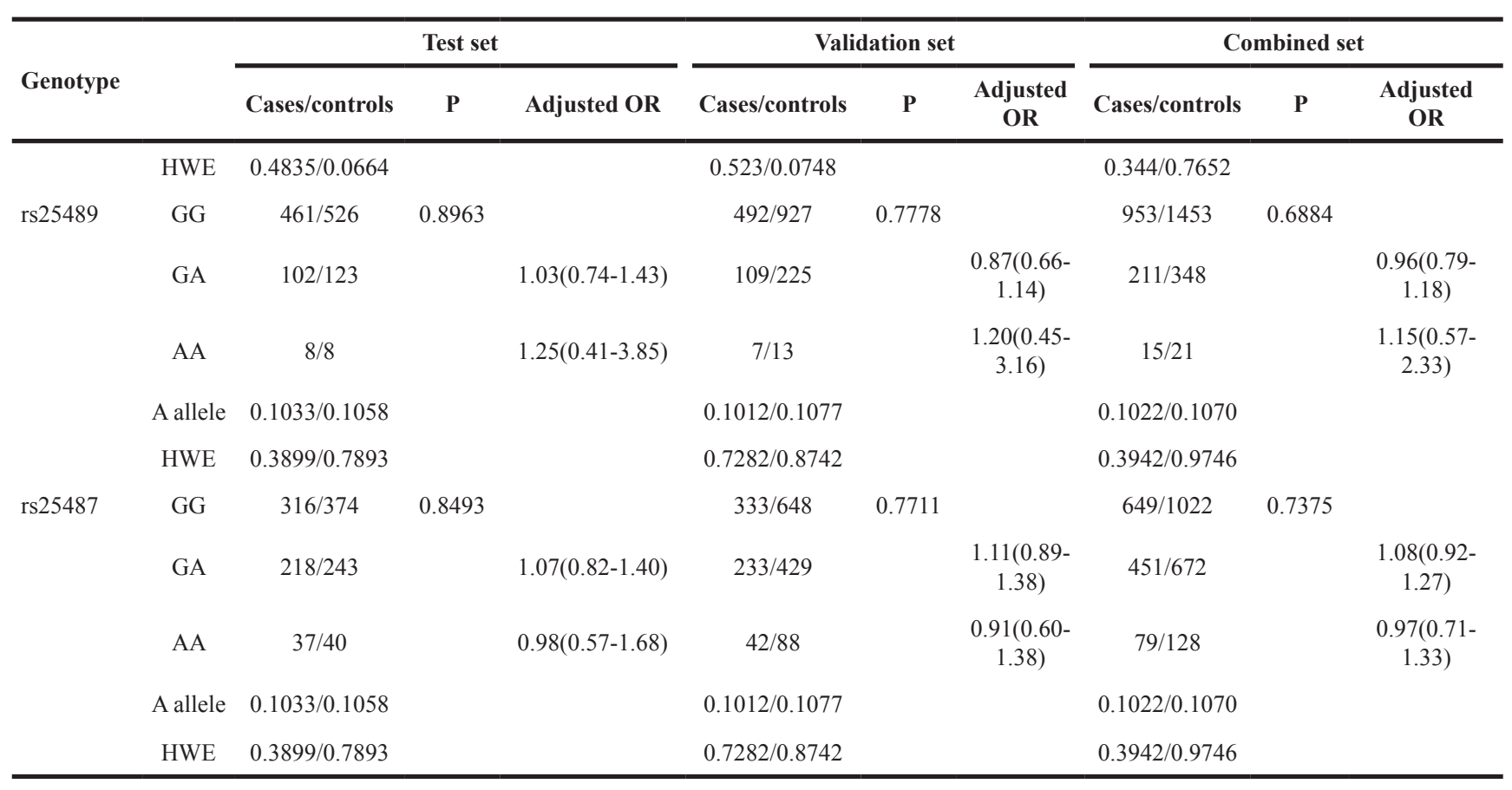

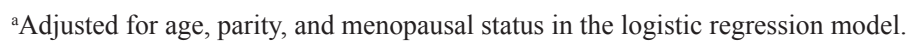

Table 3: Stratified analysis of XRCC1 rs3213245 genotypes associated with cervical cancer risk by the selected variables

\begin{tabular}{|c|c|c|c|c|}
\hline \multirow{2}{*}{ Variables } & \multicolumn{2}{|c|}{ Genotypes (cases/controls) } & \multirow{2}{*}{$P$} & \multirow{2}{*}{ Adjusted OR (95\% CI) } \\
\hline & TT & $\mathrm{TC} / \mathrm{CC}$ & & \\
\hline \multicolumn{5}{|l|}{ Age (years) } \\
\hline$\leq 49$ & $503 / 696$ & $129 / 205$ & 0.2744 & $0.82(0.63-1.07)$ \\
\hline$>49$ & $452 / 646$ & $95 / 275$ & $<.0001$ & $0.47(0.36-0.62)$ \\
\hline \multicolumn{5}{|l|}{ Parity } \\
\hline $0-1$ & $522 / 915$ & $125 / 331$ & 0.0005 & $0.68(0.54-0.87)$ \\
\hline$\geq 2$ & $412 / 322$ & $93 / 127$ & 0.0003 & $0.53(0.39-0.73)$ \\
\hline \multicolumn{5}{|l|}{ Abortion } \\
\hline No & $330 / 439$ & $70 / 169$ & 0.0002 & $0.51(0.37-0.72)$ \\
\hline Yes & $588 / 773$ & $141 / 271$ & 0.0012 & $0.65(0.51-0.83)$ \\
\hline \multicolumn{5}{|l|}{ Menopausal status } \\
\hline Premenopausal & $505 / 679$ & $119 / 233$ & 0.003 & $0.69(0.53-0.90)$ \\
\hline Postmenopausal & $429 / 567$ & $97 / 221$ & $<.0001$ & $0.55(0.42-0.73)$ \\
\hline \multicolumn{5}{|l|}{ Stage } \\
\hline $\mathrm{I} / \mathrm{II}$ & $912 / 1342$ & $216 / 480$ & $<.0001$ & $0.63(0.52-0.76)$ \\
\hline III/IV & $30 / 1342$ & $7 / 480$ & 0.3092 & $0.54(0.24-1.23)$ \\
\hline
\end{tabular}

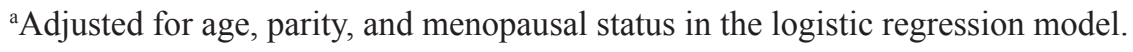


XRCC1 transcription. We next performed sequential ChIP (Re-ChIP) assay to verify this hypothesis. Interestingly, we found that the XRCC1 rs3213245 SNP might affect the binding ability of $\mathrm{Sp} 1$ and Krox-20 complex to the chromatin (Figure 1F-1G).

\section{Sp1 regulated the transcription of the XRCC1 by recruiting Krox-20 to the rs3231245 mutation region}

The siRNA knockdown experiments were then used to explore the manner of $\mathrm{Sp} 1$ and Krox-20 binding to the XRCC1 promoter region in HeLa (HPV18-positive), SiHa (HPV16-positive), and C-33A (HPV-negative) cells. We found that Sp1 might bind with the rs3213245 mutation region when transfected with negative control or Krox-20 siRNA, rather than Sp1 siRNA (Figure 2A, 2D, $2 \mathrm{G})$. However, Krox-20 failed to bind with the rs 3213245 mutation region when transfected with $\mathrm{Sp} 1$ siRNA (Figure 2B, 2E, 2H). The knockdown was confirmed by Western blot (Figure 2C, $2 \mathrm{~F}$ and 2I). In addition, the XRCC1 mRNA level of cervical cancer patients was determined to verify the transcriptional regulation of XRCC1 by the Sp1-Krox-20 complex in vivo. The frequency distribution of $\mathrm{CC}, \mathrm{CT}$, and TT was 2,18 , and 20 , respectively. Results showed that individuals with CT/TT genotypes at the rs3213245 had significantly lower XRCC1 levels than those with the CC genotype (Supplementary Figure 1).

\section{DISCUSSION}

Cervical cancer is still the leading cause of cancerrelated deaths among women. Dysfunctions of DNA repair pathways, particularly the BER pathway, have also been considered one of the major causes of cancer [2]. However, few studies have focused on the association between the functional polymorphisms in the BER pathway and cervical cancer susceptibility. The present study demonstrated that genetic variants in the BER pathway are associated with the risk of cervical cancer.

Results also showed that the XRCC1 rs 3213245 C genotype decreases the risk of cervical cancer by upregulating the tumoral $X R C C 1$ transcription in cervical cancer patients. The ChIP and re-ChIP assays also demonstrated that the Sp1-Krox-20 complex prefers binding to the XRCC1 rs3213245 C genotype, thereby enhancing its transcription (Figure 3 ).

In the present study, we found that common polymorphisms of HOGG1, ADPRT and APE1 genes were not associated with the risk of cervical cancer. Moreover, ADPRT polymorphism was reported to be significantly associated with kinds of cancers $[19,20]$. In the present study, the results of ADPRT rs 1136410 genotypes associated with the risk of cervical cancer in two independent retrospective cohorts were different. It suggested that the polymorphisms of BER genes might be cellular-dependent because of different racial background [21]. Gene-environment interaction might play important
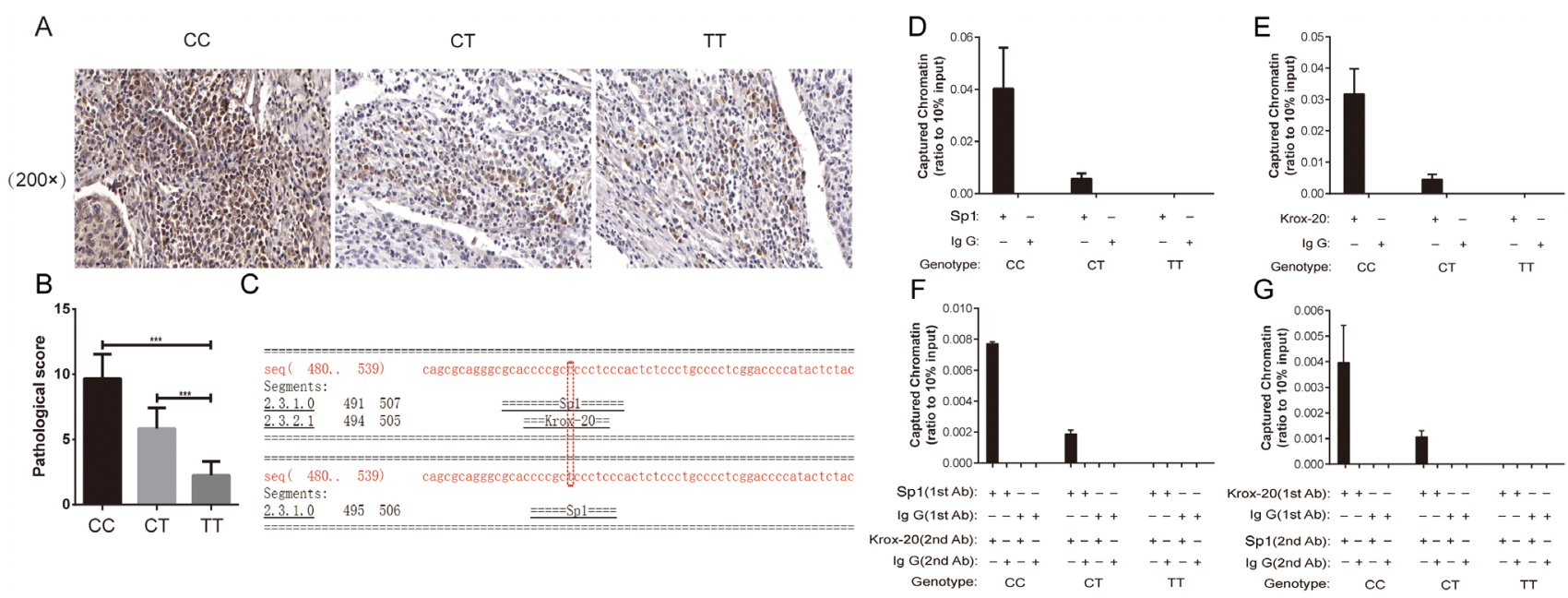

Figure 1: XRCC1 rs3213245 CC genotype promoted tumoral XRCC1 expression in patients. IHC assay reveals that massive XRCC1-positive cells are observed in sections from cervical cancer patients carrying the XRCC1 rs3213245 CC genotype. (A) Representative IHC images and (B) IHC staining scores are shown. $* P<0.05$. (C) XRCC1 -77 site located in the Sp1 binding motif according to the Alibaba2 Bioinformatics database. (D) A Sp1 ChIP assay was performed with different XRCC1 rs3213245 genotypes in cervical cancer patients. (E) Krox-20 ChIP assay was performed with different XRCC1 rs3213245 genotypes in cervical cancer patients. (F and $\mathbf{G}$ ) Re-ChIP experiments were performed on formaldehyde-crosslinked DNA prepared from the human peripheral white blood cells of cervical cancer patients. For all genotypes, the chromatin-Sp1 complex was re-immunoprecipitated using anti-human Krox-20 (F), or the chromatin-Krox-20 complex was re-immunoprecipitated using anti-human Sp1 (G). The antibodies were used as indicated. Equal amounts of input and immunoprecipitated DNA were quantified using real-time quantitative PCR. 


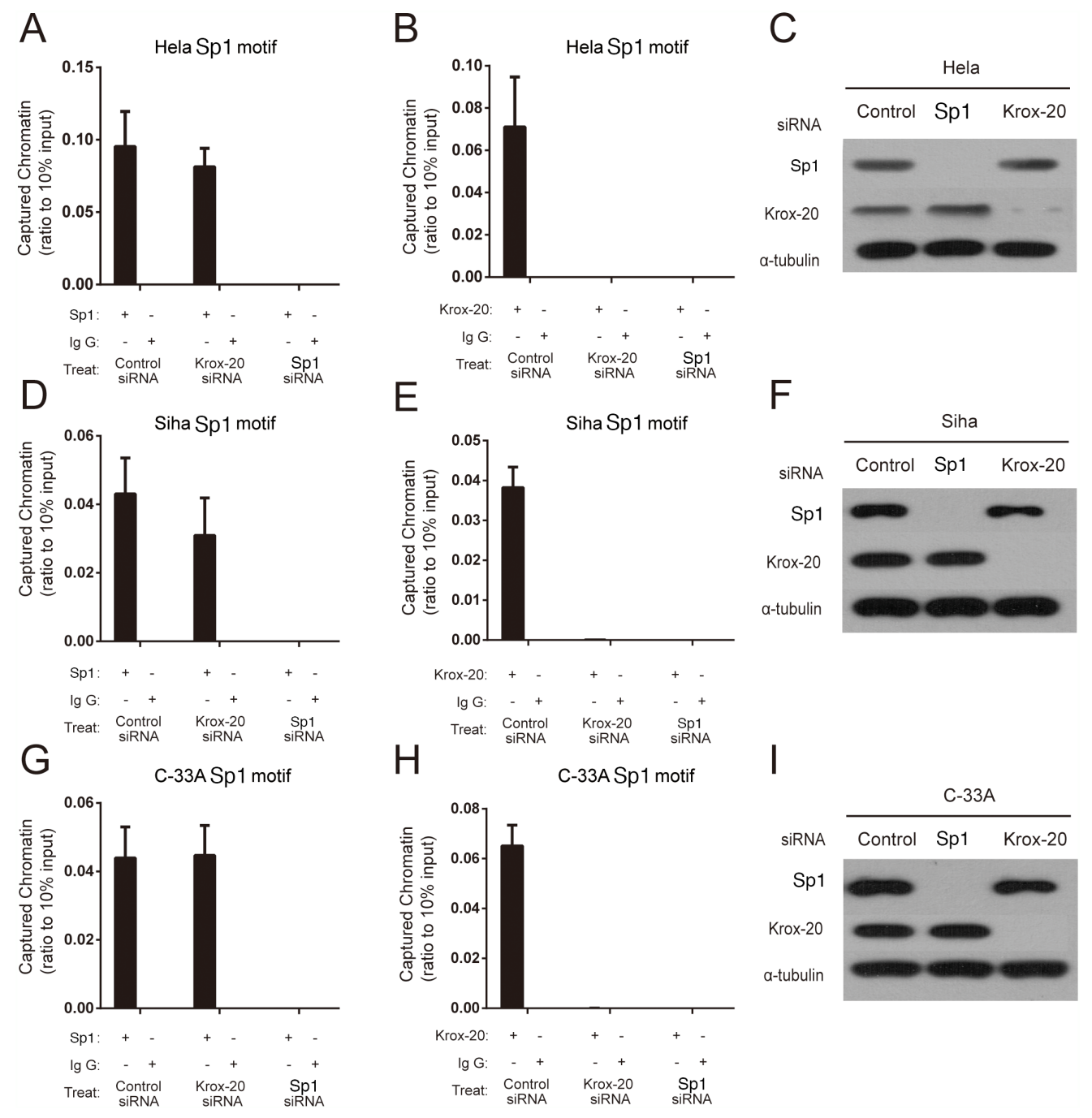

Figure 2: Sp1 regulated the transcription of the XRCC1 by recruiting Krox-20 to the rs3231245 mutation region. (A, $\mathbf{B}, \mathbf{D}, \mathbf{E}, \mathbf{G}$ and $\mathbf{H}$ ) Binding affinity of Sp1 and Krox-20 to chromatin. (C, F and I) Confirmation of protein expression of Sp1 and Krox-20 in siRNA-transfected cells by Western blot analysis.

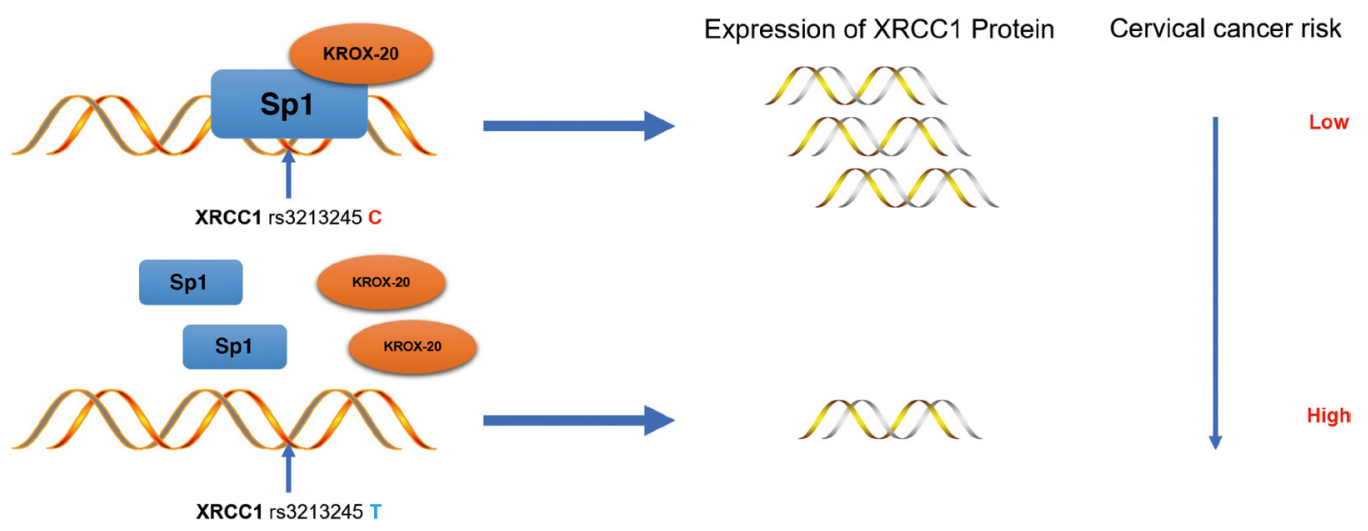

Figure 3: Schematic model of the regulations among rs3213245 and XRCC1 involved in cervical cancer development. The transcription factor Krox-20 was recruited to the Spl binding motif. The rs3213245 C>T polymorphism may change the binding affinity of the transcription factor Sp1-Krox-20 complex to the mutation region, thereby regulating the expression of the XRCC1 gene and ultimately leads to cervical cancer development. 
role in the risk of cervical cancer. Larger studies should be taken to validate the association between ADPRT rs1136410 polymorphism and the risk of cervical cancer.

Further siRNA knockdown experiments showed that Krox-20 was recruited to Sp1 binding motif in both HeLa (HPV18-positive), SiHa (HPV16-positive), and C-33A (HPV-negative) cervical cancer cells in vitro knockdown experiments. This also confirmed that HPVs infection is not a necessary Etiological Factor for cervical cancer proposed by Wu et al. [22].

In conclusion, we have shown that the transcription factor Krox-20 was recruited to the XRCC1 rs3213245 mutation region and regulated the transcription of the $X R C C 1$ gene by interacting with $\mathrm{Sp} 1$, ultimately mediated cervical cancer development.

\section{MATERIALS AND METHODS}

\section{Study subjects}

This study comprised two independent retrospective cohorts. The testing cohort involved 571 cervical cancer patients and 657 matched cancer-free controls recruited from the First Affiliated Hospital of Nanjing Medical University between January 2007 and December 2010. The subjects in the validation cohort were recruited from hospitals in Nantong City between January 2009 and August 2016. This group comprised 608 cervical cancer patients and 1165 matched cancer-free controls. All included cases were newly and histopathologically diagnosed with primary cervical cancer. None of the patients had received chemotherapy or radiotherapy prior to enrolment. Each of the subjects provided informed consent. The experimental procedures were authorized by the ethics review board of the Southeast University.

\section{Genotype analysis}

The functional genetic polymorphisms of the key components (i.e., HOGG1, XRCC1, ADPRT, and APE1) in the BER pathway were detected. The genomic DNA of the subjects in the testing cohort was extracted from the peripheral blood lymphocytes. The DNA of the validation cohort was extracted from the paraffin-embedded tissues. The polymorphisms of the selected genes were genotyped by the TaqMan allelic discrimination method by using the ABI $7900 \mathrm{HT}$ real-time PCR system (Applied Biosystems, CA, USA). The following primers were used to amplify the target fragments: rs1136410F5'-GACTGTAGGCCACCTCGATGTC-3'/ R5'-AGTCTGTCTCATTCACCATGATACCT-3', rs3213245F5'-TCTGGAGAGGCGCGACTG-3'/ R5'-CAGAAGGATGAGGTAGAGTATGGG-3', rs1799782F5'-GAGGATGAGAGCGCCAACTC-3'/ R5'-TCACTCAGGACCCACGTTGTC-3', rs
R5'-CTTCTCCTCGGGGTTTGCC-3', rs25487F5'AAGGAGTGGGTGCTGGACTGT-3'/ R5'-CCAGCACAGGATAAGGAGCAG-3', rs1760944F5'-AGCCTTCTCCACTGTTTTTTTCC/ R5'-CAGCACATTGTGTGACACTGACTT-3', rs1130409F5'-CCCGGCCTTCCTGATCAT-3'/R5'CCCACCTCTTGATTGCTTTCC-3', and rs1052133F5'CCTCCTACAGGTGCTGTTCAGTG-3'/R5'-

ACCCTTTCTGCGCTTTGCT-3'. Three positive control and negative control samples were used for the quality control of each amplification. At least $10 \%$ of the samples were randomly selected for further confirmation. The results were $100 \%$ concordant.

\section{Immunohistochemistry (IHC)}

Tissues obtained from the cervical cancer patients were coated on $0.4 \mu \mathrm{m}$ sections. IHC analysis was conducted as previously reported [23]. The sections were incubated with mouse XRCC1 (1:100 dilution, BOSTER) monoclonal antibodies incubated overnight at $4^{\circ} \mathrm{C}$. XRCC 1 staining in the sections was independently evaluated by two pathologists by using a semi-quantitative immunoreactivity score [24].

\section{Cell culture}

HeLa, SiHa, and C-33A cells were cultured at $37^{\circ} \mathrm{C}$ in complete DMEM media (HyClone, Logan, UT, USA) with 10\% FBS (Sigma, ST. Louis, MO, USA) and penicillin $\left(100 \mathrm{U} \mathrm{ml}^{-1}\right) /$ streptomycin $\left(100 \mathrm{ug} \mathrm{ml}^{-1}\right)$ (HyClone, Logan, UT, USA) in 5\% CO2. The cells were periodically tested and validated to be mycoplasma free. For siRNA transfection experiments, three groups were separately transfected using Lipofectamine 2000 reagent (Invitrogen, Carlsbad, CA, USA), with $1 \mu \mathrm{g}$ negative control, Sp1, and Krox-20 siRNA (Genepharma, Shanghai, China) in accordance with the manufacturer's protocol. Cells were collected $48 \mathrm{~h}$ after transfection.

\section{Western blot (WB)}

Total protein were extracted from cell samples as described before [25]. Proteins of cells were analyzed by immunoblots. Three primary antibodies were employed in the experiments: human Sp1 (1:1000 dilution; CST, USA), Krox-20(1:1000 dilution; abcam, USA), and $\alpha$-tubulin (1:1000 dilution; Sigma, USA).

\section{Chromatin immunoprecipitation (ChIP) and Re- ChIP assays}

Human peripheral white blood cells from the cervical cancer patients were used for the ChIP and ReChIP analyses according to the standard protocol [26]. Briefly, the antibody against Sp1, Krox-20, or control IgG were immunoprecipitated with the chromatin fragments 
in ChIP assay. For re-ChIP, the samples were diluted 10 times with the dilution buffer and subjected to the ChIP procedure again after the elution of the first ChIP. The chromatin-Splcomplex was re-immunoprecipitated using anti-human Krox-20, whereas the chromatinKrox-20 complex was re-immunoprecipitated using antihuman Sp1. Quantitative PCR was performed to analyze the precipitated genomic DNA using the following human XRCC1 rs3213245 (-77TC) promoter primers: 5'-AGGAAACGCTCGTTGCTAAG-3' (forward) and 5'-TGGCCAGAAGGATGAGGTAG-3' (reverse) for rs3213245.

\section{Reverse transcription-quantitative real-time PCR (RT-PCR)}

Total RNAs were extracted from frozen tissue samples of patients with cervical cancer using Trizol reagent (Invitrogen, US) and treated by DNase / RNasefree Deionized water (Tiangen, Beijing, China). cycA was used as internal controls in SYBR ${ }^{\circledR}$ Green Realtime PCR Master Mix-Plus kits (Toyobo, Osaka, Japan). The expression level of XRCC1 were amplified with PCR primers (Takara, Shanghai, China) and quantitative using the Quant Studio 6 Flex system (Applied Biosystems, Life Technologies, USA).

\section{Statistical analysis}

The $\chi^{2}$ test was used to investigate the HardyWeinberg equilibrium of the controls' genotype frequencies and the frequency distribution of the selected demographic variables and genotypes. Multivariate logistic regression was used to calculate the odds ratio values and 95\% confidence interval. $P<0.05$ was considered statistically significant.

\section{ACKNOWLEDGMENTS AND FUNDING}

This work was supported by National Natural Science Foundation of China (Grant No. 91643109, 81302502 and 81472938), National Key Research and Development Program of China (2017YFC0211603), the Thousand Young Talents Plan of China, the Natural Science Foundation of Jiangsu Province (BK20171367 and BK20151418), the Fund of the Distinguished Talents of Jiangsu Province (BK20150021), the Fund of the Distinguished Professor of Jiangsu Province, the Six talent peaks project in Jiangsu Province (2016-WSN-002), Specialized Research Fund for the Doctoral Program of Higher Education of China (20130092120063), Nantong Municipal Science and Technology Plan (qyz15003), and the Fundamental Research Funds for the Central Universities. The
National Institute of Environmental Health Sciences (NIEHS), R01 ES10563, R01 ES07331 and R01 ES020852. The Fund of Post-graduate Innovative Talents in Jiangsu Province (KYZZ16_0137).

\section{CONFLICTS OF INTEREST}

The authors declare that they have no conflicts of interest.

\section{REFERENCES}

1. Wood RD, Mitchell M, Lindahl T. Human DNA repair genes, 2005. Mutat Res. 2005; 577:275-83. https://doi. org/10.1016/j.mrfmmm.2005.03.007.

2. Jiricny J, Marra G. DNA repair defects in colon cancer. Curr Opin Genet Dev. 2003; 13:61-9.

3. Cao Q, Qin C, Meng X, Ju X, Ding Q, Wang M, Zhu J, Wang W, Li P, Chen J, Zhang Z, Yin C. Genetic polymorphisms in APE1 are associated with renal cell carcinoma risk in a Chinese population. Mol Carcinog. 2011; 50:863-70. https://doi.org/10.1002/mc.20791.

4. Kang H, Dai Z, Ma X, Ma L, Jin Y, Liu X, Wang X. A genetic variant in the promoter of APE1 gene $(-656 \mathrm{~T}>\mathrm{G})$ is associated with breast cancer risk and progression in a Chinese population. Gene. 2013; 531:97-100. https://doi. org/10.1016/j.gene.2013.08.052.

5. Aburatani H, Hippo Y, Ishida T, Takashima R, Matsuba C, Kodama T, Takao M, Yasui A, Yamamoto K, Asano M. Cloning and characterization of mammalian 8-hydroxyguanine-specific DNA glycosylase/apurinic, apyrimidinic lyase, a functional mutM homologue. Cancer Res. 1997; 57:2151-6.

6. Jiao X, Huang J, Wu S, Lv M, Hu Y, Jianfu, Su X, Luo C, Ce B. hOGG1 Ser326Cys polymorphism and susceptibility to gallbladder cancer in a Chinese population. Int J Cancer. 2007; 121:501-5. https://doi.org/10.1002/ijc.22748.

7. Zhao H, Qin C, Yan F, Wu B, Cao Q, Wang M, Zhang Z, Yin C. hOGG1 Ser326Cys polymorphism and renal cell carcinoma risk in a Chinese population. DNA Cell Biol. 2011; 30:317-21. https://doi.org/10.1089/dna.2010.1135.

8. Campalans A, Marsin S, Nakabeppu Y, O'Connor TR, Boiteux S, Radicella JP. XRCC1 interactions with multiple DNA glycosylases: a model for its recruitment to base excision repair. DNA Repair (Amst). 2005; 4:826-35. https://doi.org/10.1016/j.dnarep.2005.04.014.

9. Mei J, Duan HX, Wang LL, Yang S, Lu JQ, Shi TY, Zhao Y. XRCC1 polymorphisms and cervical cancer risk: an updated meta-analysis. Tumour Biol. 2014; 35:1221-31. https://doi.org/10.1007/s13277-013-1163-7.

10. Li Y, Liu F, Tan SQ, Wang Y, Li SW. X-ray repair crosscomplementing group 1 (XRCC1) genetic polymorphisms and cervical cancer risk: a huge systematic review and 
meta-analysis. PLoS One. 2012; 7:e44441. https://doi. org/10.1371/journal.pone.0044441.

11. Liu L, Yuan P, Liu L, Wu C, Zhang X, Guo H, Zhong R, $\mathrm{Xu} \mathrm{Y,} \mathrm{Wu} \mathrm{J,} \mathrm{Duan} \mathrm{S,} \mathrm{Rui} \mathrm{R,} \mathrm{Wu} \mathrm{T,} \mathrm{Nie} \mathrm{S,} \mathrm{et} \mathrm{al.} \mathrm{A} \mathrm{functional}$ $-77 \mathrm{~T}>\mathrm{C}$ polymorphism in XRCC1 is associated with risk of breast cancer. Breast Cancer Res Treat. 2011; 125:479-87. https://doi.org/10.1007/s10549-010-0959-z.

12. Schneider J, Classen V, Helmig S. XRCC1 polymorphism and lung cancer risk. Expert Rev Mol Diagn. 2008; 8:76180. https://doi.org/10.1586/14737159.8.6.761.

13. Hao B, Miao X, Li Y, Zhang X, Sun T, Liang G, Zhao Y, Zhou Y, Wang H, Chen X, Zhang L, Tan W, Wei Q, et al. A novel T-77C polymorphism in DNA repair gene XRCC1 contributes to diminished promoter activity and increased risk of non-small cell lung cancer. Oncogene. 2006; 25:3613-20. https://doi.org/10.1038/sj.onc.1209355.

14. Chu S. Transcriptional regulation by post-transcriptional modification--role of phosphorylation in $\mathrm{Sp} 1$ transcriptional activity. Gene. 2012; 508:1-8. https://doi.org/10.1016/j. gene.2012.07.022.

15. Gilmour J, Assi SA, Jaegle U, Kulu D, van de Werken H, Clarke D, Westhead DR, Philipsen S, Bonifer C. A crucial role for the ubiquitously expressed transcription factor $\mathrm{Sp} 1$ at early stages of hematopoietic specification. Development. 2014; 141:2391-401. https://doi.org/10.1242/dev.106054.

16. Li L, Davie JR. The role of Sp1 and Sp3 in normal and cancer cell biology. Ann Anat. 2010; 192:275-83. https:// doi.org/10.1016/j.aanat.2010.07.010.

17. Kwon YJ, Baek HS, Ye DJ, Shin S, Kim D, Chun YJ. CYP1B1 enhances cell proliferation and metastasis through induction of EMT and activation of Wnt/betacatenin signaling via $\mathrm{Sp} 1$ upregulation. PLoS One. 2016; 11:e0151598. https://doi.org/10.1371/journal. pone. 0151598 .

18. Suske G. The Sp-family of transcription factors. Gene. 1999; 238:291-300.

19. Huehls AM, Wagner JM, Huntoon CJ, Geng L, Erlichman C, Patel AG, Kaufmann SH, Karnitz LM. Poly (ADP-Ribose) polymerase inhibition synergizes with 5-fluorodeoxyuridine but not 5-fluorouracil in ovarian cancer cells. Cancer Res.
2011; 71:4944-54. https://doi.org/10.1158/0008-5472. CAN-11-0814.

20. Smith TR, Liu-Mares W, Van Emburgh BO, Levine EA, Allen GO, Hill JW, Reis IM, Kresty LA, Pegram MD, Miller MS, Hu JJ. Genetic polymorphisms of multiple DNA repair pathways impact age at diagnosis and TP53 mutations in breast cancer. Carcinogenesis. 2011; 32:135460. https://doi.org/10.1093/carcin/bgr117.

21. Li K, Li W. Association between polymorphisms of XRCC1 and ADPRT genes and ovarian cancer survival with platinum-based chemotherapy in Chinese population. Mol Cell Biochem. 2013; 372:27-33. https://doi.org/10.1007/ s11010-012-1442-4.

22. Wu S, Wang S, Fu Y, Tang W, Jin H, Meng Q, Zhang C, Cui M, Cao X, Li X, Zhang Z, Chen R. 6.513 a novel mechanism of rs763110 polymorphism contributing to cervical cancer risk by affecting the binding affinity of $\mathrm{C} /$ EBPbeta and OCT1 complex to chromatin. Int J Cancer. 2017; 140:756-63. https://doi.org/10.1002/ijc.30490.

23. Fu YP, Kohaar I, Rothman N, Earl J, Figueroa JD, Ye Y, Malats N, Tang W, Liu L, Garcia-Closas M, Muchmore B, Chatterjee N, Tarway M, et al. Common genetic variants in the PSCA gene influence gene expression and bladder cancer risk. Proc Natl Acad Sci U S A. 2012; 109:4974-9. https://doi.org/10.1073/pnas.1202189109.

24. Wang S, Wu X, Chen Y, Zhang J, Ding J, Zhou Y, He S, Tan Y, Qiang F, Bai J, Zeng J, Gong Z, Li A, et al. Prognostic and predictive role of JWA and XRCC1 expressions in gastric cancer. Clin Cancer Res. 2012; 18:2987-96. https:// doi.org/10.1158/1078-0432.CCR-11-2863.

25. Li X, Lv Y, Hao J, Sun H, Gao N, Zhang C, Lu R, Wang $\mathrm{S}$, Yin L, Pu Y, Chen R. Role of microRNA-4516 involved autophagy associated with exposure to fine particulate matter. Oncotarget. 2016; 7:45385-97. https://doi. org/10.18632/oncotarget.9978.

26. Wang S, Wu S, Meng Q, Li X, Zhang J, Chen R, Wang M. FAS rs2234767 and rs1800682 polymorphisms jointly contributed to risk of colorectal cancer by affecting Sp1/ STAT1 complex recruitment to chromatin. Sci Rep. 2016; 6:19229. https://doi.org/10.1038/srep19229. 